ISSN 1112-9867

Available online at http://www.jfas.info

\title{
SUPERALLOYS: AN INTRODUCTION WITH THERMAL ANALYSIS
}

\author{
S. S. Raza
}

Department of Materials Science and Engineering, KTH, The Royal Institute of Technology, SE10044, Stockholm, Sweden

Received: 23 April 2015 / Accepted: 21 August 2015 / Published online: 1 September 2015

\begin{abstract}
Solidification studies of Alloy 718, Allvac 718plus and Waspaloy have been of great interest in the present study. Alloy 718 is a precipitation strengthened nickel-iron based alloy. Waspaloy, another precipitation strengthened nickel base superalloy, has a very good strength at temperatures up to $\sim 750{ }^{\circ} \mathrm{C}$ whereas Allvac 718Plus is a newly developed nickel based precipitation strengthened superalloy which retains good mechanical properties at up to $\sim 700$ ${ }^{\circ} \mathrm{C}$. These three alloys were investigated in terms of how their respective solidification process reveals upon cooling. Latent heat of solidification has been estimated for all three alloys.Differential thermal analyses (DTA) have been used to approach the task. It was seen that Waspaloy has the smallest solidification range whereas Allvac 718Plus has the largest solidification interval in comparison.
\end{abstract}

Keywords: Superalloys; Phase reactions; Differential Thermal Analysis; Latent heat of Solidification; Solidification interval.

Author Correspondence, e-mail: sshahzadraza@hotmail.com

doi: http://dx.doi.org/10.4314/jfas.v7i3.5

\section{INTRODUCTION}

A superalloy is a type of alloy that retains excellent mechanical properties at elevated temperature (super good properties at elevated temperatures). This includes excellent creep 
resistance, corrosion and oxidation resistance. The base metal is usually nickel, cobalt or nickeliron. Superalloys are classified into three classes; nickel-based, cobalt-based and iron-based superalloys. These alloys are commonly used in the aerospace or gas turbine industry, in parts that requires excellent mechanical properties at elevated temperatures. Superalloys are also utilized in the chemical and petrochemical industries apart from the gas turbine industry. In aircraft gas turbine components these superalloys may find their applications in disks, bolts, shafts, cases, blades, vanes, combustors, afterburners etc (basically anywhere where the temperature is above $\sim 500^{\circ} \mathrm{C}$ ).

The major applications of superalloys are categorized below; the bulk of tonnage is used in gas turbines:

- In aircraft gas turbine they find their applications in disks, combustion chambers, bolts, casings, shafts, exhaust systems, cases, blades, vanes, burner cans, afterburners and in thrust reversers.

- In steam turbine power plants bolts, blades, stack gas re-heaters are made from these alloys.

- In reciprocating engines; turbochargers, exhaust valves, hot plugs and valve seat inserts are made from these alloys.

- During metal processing; hot-work tools and dies and casting dies are made from these alloys.

- In medical applications, dentistry uses and prosthetic devices are made from these alloys.

- In space vehicles: aerodynamically heated skins and rocket engine parts are made from these alloys.

- In heat-treating equipment; trays, fixtures, conveyor belts, baskets, fans, furnace mufflers are made from them.

- In nuclear power systems; control rod drive mechanisms and valve stems, springs, ducting are made from nickel based superalloys.

- In chemical and petrochemical industries; bolts, fans, valves, reaction vessels, piping and pumps are made from these alloys.

- In pollution control equipment they are utilised in scrubbers.

-In metals processing mills they are used in ovens, afterburners and exhaust fans.

-In coal gasification and liquefaction systems they are used in heat exchangers, re-heaters andin piping systems.

The nickel-base superalloys are considered to be complex because they incorporate as many as a dozen of elements. In addition, deleterious elements such as silicon, phosphorus, sulfur, oxygen, 
and nitrogen must be controlled through appropriate melting practices. Other trace elements such as selenium, bismuth, and lead, must be held to a very small (ppm) levels in critical parts. Many wrought nickel-based superalloys contain 10 to $20 \% \mathrm{Cr}$, up to about $8 \% \mathrm{Al}$ and Ti combined, 5 to $15 \% \mathrm{Co}$, and small amounts of boron, zirconium, magnesium, and carbon. Other common additions are molybdenum, niobium, and tungsten, all of which play dual roles as strengthening solutes and carbide formers. Chromium and aluminum are also necessary to improve surface stability through the formation of $\mathrm{Cr}_{2} \mathrm{O}_{3}$ and $\mathrm{Al}_{2} \mathrm{O}_{3}$, respectively.

\subsection{Microstructure and strengthening mechanisms}

The major phases that may be present in nickel-base alloys are:

- Gamma matrix, $\gamma$, in which the continuous matrix is an FCC nickel-base nonmagnetic phase that usually contains a high percentage of solid-solution elements such as cobalt, iron, chromium, molybdenum, and tungsten. All nickel-base alloys contain this phase as the matrix.

- Gamma prime, $\gamma^{\prime}$, in which aluminum and titanium are added in amounts required to precipitate FCC $\gamma^{\prime}\left(\mathrm{Ni}_{3} \mathrm{Al}\right.$, Ti), which precipitates coherently with the austenitic gamma matrix. Other elements, notably niobium, tantalum, and chromium, also enter $\gamma^{\prime}$. This phase is required for high-temperature strength and creep resistance.

- Gamma double prime, $\gamma^{\prime \prime}$, in which nickel and niobium combine in the presence of iron to form body centered tetragonal (BCT) $\mathrm{Ni}_{3} \mathrm{Nb}$, which is coherent with the gamma matrix, while including large mismatch strains of the order of $2.9 \%$. This phase provides very high strength at low to intermediate temperatures, but is unstable at temperatures above about $650{ }^{\circ} \mathrm{C}\left(1200{ }^{\circ} \mathrm{F}\right)$. This precipitate is found in nickel-iron alloys.

- Grain boundary $\gamma^{\prime}$, a film of $\gamma^{\prime}$ along the gain boundaries in the stronger alloys, produced by heat treatments and service exposure. This film is believed to improve rupture properties.

- Carbides, in which carbon that is added in amounts of about 0.02 to $0.2 \mathrm{wt} \%$ combines with reactive elements, such as titanium, tantalum, hafnium, and niobium, to form metal carbides (MC). During heat treatment and service, these MC carbides tend to decompose and generate other carbides, such as $\mathrm{M}_{23} \mathrm{C}_{6}$ and/or $\mathrm{M}_{6} \mathrm{C}$, which tend to form at grain boundaries. Carbides in nominal solid-solution alloys may form after extended service exposures.

- Borides, a relatively low density of boride particles formed when boron segregates to grain boundaries. 
- Topologically close-packed (TCP) type phases, which are plate-like or needle-like phases such as $\sigma$, and $\mu$ that may form for some compositions and under certain conditions. These cause lowered rupture strength and ductility.

The strengthening mechanisms in superalloys are usually governed by solid solution and/or precipitation strengthening [1]. These alloys can be used up to a higher fraction of their melting points than any other commercially available alloy system. Refractory materials have higher melting points than superalloys but don't have the desired characteristics and consequently not as widely used. It should be noted that the superb strength of superalloys are not only related to its chemistry but also to the primary melting, forming and casting techniques. Heat treatment procedures may considerably improve the properties. Many alloying elements are added to these alloys, all with different purposes, and these may be as many as 14 in some cases [2].

\subsection{Phase transformations}

During the solidification process of the present nickel and nickel iron base superalloys, there are three main reactions:

1. Liquid $\rightarrow$ Gamma

2. Liquid $\rightarrow$ Gamma $+\mathrm{MC}$

3. $\mathrm{L} \rightarrow$ Gamma + Laves (not applicable for Waspaloy)

In Alloy 718 the first thing to take place apart from nucleation of nitrides is the Gamma matrix phase to nucleate. During solidification the liquid becomes enriched in niobium and carbon which result in formation of a non-invariant Gamma/MC eutectic reaction proceeding with more enrichment of $\mathrm{Nb}$ while depleting $\mathrm{C}$ resulting in a final reaction, Liquid through Gamma/Laves eutectic reaction which is not encountered in Waspaloy [3].

\section{RESULTS AND DISCUSSION}

The solidification sequence of the investigated nickel based superalloys starts with a primary precipitation of $\gamma$-phase, followed by one or two final reactions. The first reaction to take place after primary $\gamma$-phase is the formation of MC precipitates which in turn is followed by presumably Laves phase in Alloy 718 and Allvac 718Plus. The evaluation is based on the temperature difference between the sample and the reference, as a function of the temperature of the sample. 
Figure1 shows the DTA thermograph for Alloy 718 during the cooling sequence as plotted in Microsoft Excel. The differential curve is denominated by the right hand side axis. An abrupt deviation in the slope of the differential curve is around $\sim 1325^{\circ} \mathrm{C}$ and is disclosed at a cooling rate of $6{ }^{\circ} \mathrm{C} / \mathrm{min}$. This is most probably associated with the primary nucleation of the $\gamma$ phase and the start of solidification for Alloy 718 .

The second noticeable deviation (a peak) is around $1250{ }^{\circ} \mathrm{C}$ for Alloy 718 which corresponds to the precipitation of $\mathrm{MC}$ as shown in figure1. The final precipitation event; i.e. the precipitation of Laves phase occurs below $1170{ }^{\circ} \mathrm{C}$ depicted by a solid hump in figure1.

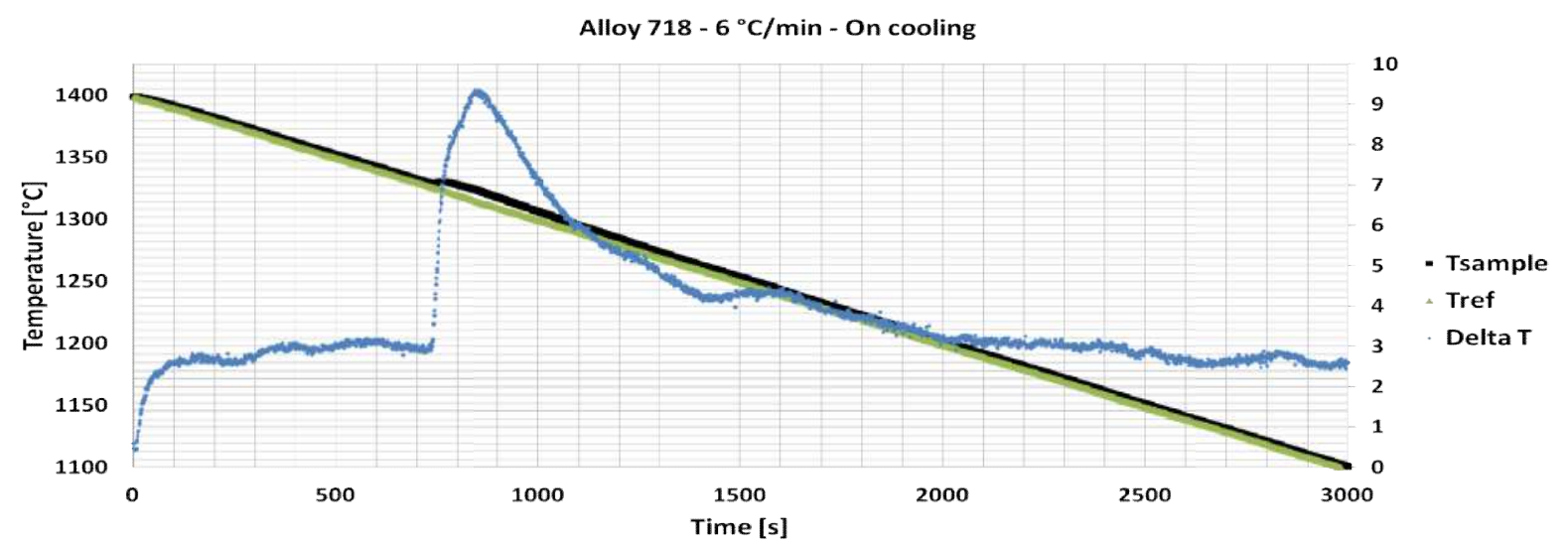

Fig.1. Cooling and differential curve for Alloy 718 at a cooling rate of $6{ }^{\circ} \mathrm{C} / \mathrm{min}$

In Allvac 718Plus and Waspaloy the first deviation is at a higher temperature. Especially Waspaloy has a higher liquidus temperature compared to Alloy 718 which can be noticed in figure 2 through 3. Allvac 718Plus do as well as Alloy 718 reveal both MC and Laves reactions upon solidification. The MC reaction takes place at around $1280{ }^{\circ} \mathrm{C}$ followed by the Laves reaction at $1150{ }^{\circ} \mathrm{C}$. 


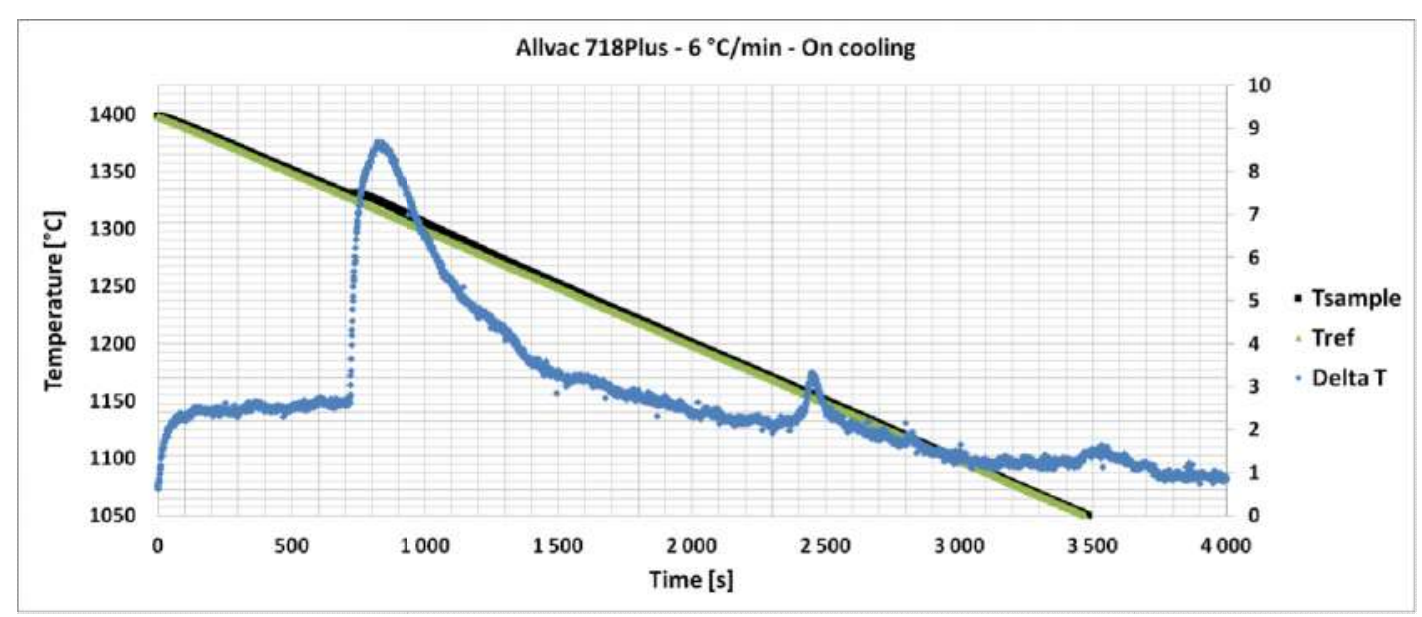

Fig.2. Cooling and differential curve for Allvac 718 Plus at a cooling rate of $6{ }^{\circ} \mathrm{C} / \mathrm{min}$ The thermographs for Waspaloy as revealed in figure 3 are smoother in comparison with Alloy 718 and Allvac 718Plus. It is therefore not as easy to determine any relevant phase reaction taking place during the cooling sequence. However, apart from the primary $\gamma$ phase revealed by the main peak in the thermographa small indication of what is presumable believed to be MC is disclosed in figure 3.

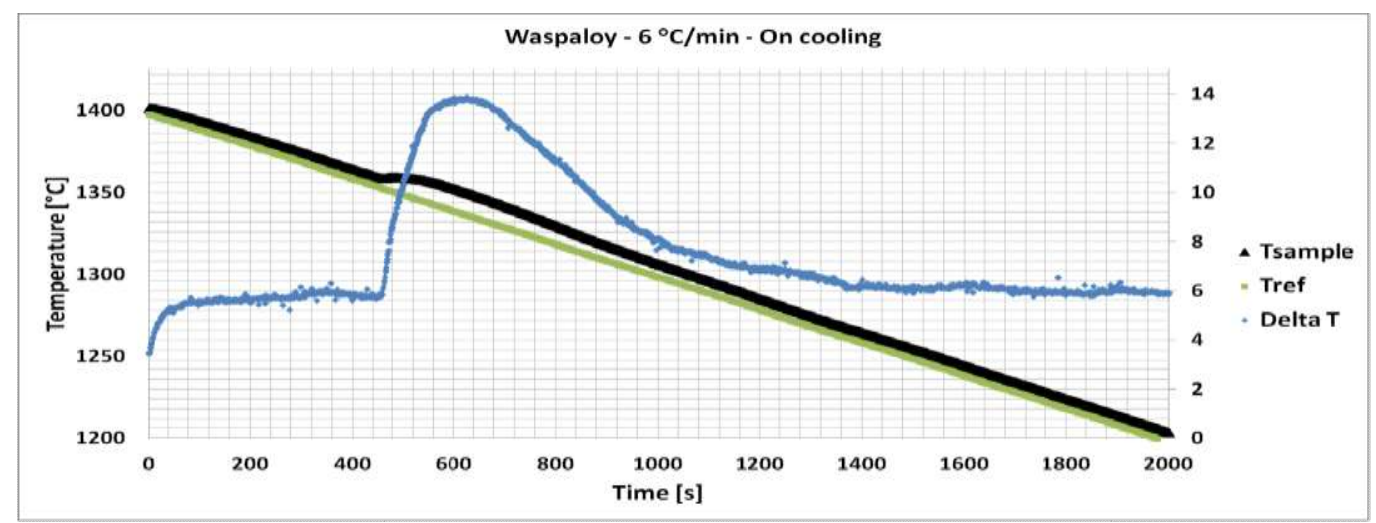

Fig.3. Cooling and differential curve for Waspaloy at a cooling rate of $6{ }^{\circ} \mathrm{C} / \mathrm{s}$

\section{EXPERIMENTAL PART}

\subsection{Test procedure and experimental setup}




\subsubsection{Differential thermal analysis setup}

Thermal analysis is a method used to measure a physical property of a material as a function of its temperature. The obtained measurements are the basis for calculations of thermodynamic properties such as enthalpy and specific heat.

Through differential thermal analysis (DTA) studies it is possible to determine phase reactions and solidification phenomenon of alloys. The heat loss to the surrounding and the influence of the thermocouple wires can more or less be neglected [4].

\subsubsection{Experimental methodology}

DTA experiments have been carried out on Alloy 718, Allvac 718Plus and Waspaloy. Each thermal cycle had a heating, soak and cooling part in which the samples have been heated up to the liquidus temperature, soaked at that temperature and then cooled down to a temperature below the solidus temperature. The starting temperature was set to $25{ }^{\circ} \mathrm{C}$ and $1400{ }^{\circ} \mathrm{C}$ as the maximum soak temperature since all of the present alloys were fully liquid at this temperature.

The samples were subjected to thermal cycle with cooling rate of $6 \mathrm{~K} / \mathrm{min}$. The soak temperature was $1400{ }^{\circ} \mathrm{C}$ for a dwell time of $\sim 300 \mathrm{~s}$. This dwell time was selected in accordance with a previous study on Alloy 718 [5].

Before testing, all samples were weighed. The ceramic tube was cut by a high speed steel cutter to fit the sample where after the sample was placed in an alumina crucible which was covered by a ceramic lid. Another crucible and thermocouple was used for the graphite reference. The whole sample assembly was covered by a ceramic shielding tube to ensure protection from contamination.

At testing, the power was switched on and start mode was initiated. The recording unit was set to heating mode. Argon and water was tapped on before starting experiments. When the temperature reached the maximum limit, after 300s of dwell time, cooling mode was initiated whereas the sample cooled to room temperature. Argon inert gas protection and water cooling were shut off and stop mode was initiated by end of experiment. The recorded data was collected and exported to an excel data sheet. Two different graphs were derived; one graph revealing the reference and furnace temperature and a second one showing their respective differential curves for analyzing the experiments. 


\subsection{EXPERIMENTAL ANALYSIS}

Thermal analysis is generally carried out to investigate the melting, solidification and phase reactions for different alloys [6]. Cooling curves can be used to determine the liquidus, solidus temperatures and also the total time of solidification [7].

The cooling curves are generally presented in a temperature and time plot. A change in slope of the curve indicates a phase reaction. Different cooling rates influence phase reaction temperatures and can be analyzed by plotted thermographs [4].

Calculation of the heat of fusion for a sample is based on the law of energy. The law of energy gives, for the case when no phase transformation is going on, i.e. before and after the solidification process. The heat of fusion can be estimated by the following equations:

$$
\begin{aligned}
& \mathrm{dQ} / \mathrm{dt}=\mathrm{V} \rho^{1} \mathrm{C}_{\mathrm{p}}{ }^{1}\left[\mathrm{dT}_{\mathrm{l}} / \mathrm{dt}\right] \\
& \mathrm{dQ} / \mathrm{dt}=\mathrm{V}\left[\rho^{1}\left(1-\mathrm{f}_{\mathrm{s}}\right) \mathrm{C}_{\mathrm{p}}{ }^{1}[\mathrm{dT} / \mathrm{dt}]\right]+\rho^{\mathrm{s}}\left[\mathrm{f}_{\mathrm{s}} \mathrm{C}_{\mathrm{p}}^{\mathrm{s}} \mathrm{dT} \mathrm{T}_{\mathrm{s}} / \mathrm{dt}+\Delta \mathrm{Hdf} / \mathrm{dt}\right] \\
& {\left[\mathrm{dT}_{\mathrm{s}} / \mathrm{dt}\right] \rho \mathrm{C}_{\mathrm{p}}{ }^{\mathrm{s}} \mathrm{V}_{\mathrm{s}}+\Delta \mathrm{H} \rho \mathrm{V}_{\mathrm{s}} \mathrm{df} / \mathrm{dt}=\mathrm{h}\left[\mathrm{T}_{\mathrm{s}}-\mathrm{T}_{\mathrm{f}}\right]} \\
& \mathrm{dQ}_{\mathrm{s}} / \mathrm{dt}=\mathrm{dQ} \mathrm{Q}_{\mathrm{l}} / \mathrm{dt} \rightarrow \mathrm{V} \rho^{1} \mathrm{C}_{\mathrm{p}}{ }^{1}\left[\mathrm{dT} \mathrm{T}_{\mathrm{l}} / \mathrm{dt}\right]=\mathrm{V}\left[\rho^{\mathrm{l}}\left(1-\mathrm{f}_{\mathrm{s}}\right) \mathrm{C}_{\mathrm{p}}{ }^{1}[\mathrm{dT} / \mathrm{dt}]+\rho^{\mathrm{s}}\left[\mathrm{f}_{\mathrm{s}} \mathrm{C}_{\mathrm{p}}^{\mathrm{s}} \mathrm{dT}_{\mathrm{s}} / \mathrm{dt}+\Delta \mathrm{Hdf} / \mathrm{dt}\right]\right]
\end{aligned}
$$

Where:

$\mathrm{dT}_{\mathrm{s}} / \mathrm{dt}=$ Cooling and heating rate of the sample

$\mathrm{Cp}=$ Specific heat of the sample

$\mathrm{V}_{\mathrm{s}}=$ Volume of the sample

$\Delta \mathrm{H}=$ Heat of fusion or latent heat of solidification

$\mathrm{df} / \mathrm{dt}=$ solidified fraction rate

$\mathrm{T}_{\mathrm{s}}=$ Sample temperature

$\mathrm{T}_{\mathrm{f}}=$ Furnace temperature

$\mathrm{h}=$ heat transfer coefficient

Heat of fusion can be estimated by using the above equations. A DTA-apparatus measures the cooling curve in terms of cooling rate of the sample, solidification time and temperature of the surroundings. The heat of fusion can be estimated by the following relation: 


$$
-\Delta \mathrm{H}_{\mathrm{s}}=\frac{\mathrm{C}_{\mathrm{p}} \mathrm{dT} / \mathrm{dt}}{\mathrm{T}_{\mathrm{s}}-\mathrm{T}_{\text {ref }}} \int_{\mathrm{s}}^{\mathrm{e}}\left(\mathrm{T}_{\mathrm{s}}-\mathrm{T}_{\mathrm{ref}}\right) \mathrm{dt}
$$

where

$\mathrm{T}_{\mathrm{s}}=$ Temperature of the sample

$\mathrm{T}_{\text {ref }}=$ Temperature of the reference

$\eta=\left(\mathrm{Ah}+\mathrm{A} \sigma \varepsilon \mathrm{T}_{\mathrm{f}}^{3}\right)$

$\rho_{\mathrm{s}}=$ Density of the sample

$\mathrm{V}_{\mathrm{s}}=$ Volume of the sample [8]

\subsection{Determining the latent heat of solidification}

The latent heat is determined for respective alloys through four different steps, as follows:

1. To determine the area underneath the thermograph

2. To determine the cooling rate

3. To determine the temperature difference in between $T_{S}$ and $T_{\text {ref }}$

4. Finally perform the calculation using equation no.5 above

\subsubsection{Estimation of latent heat of solidification}

The heat of fusion means the amount of energy needed to melt a unit mass or a mole of the substance; i.e. the total amount of energy needed to break the bonds between the atoms in a crystal lattice.

The heat of fusion values are lower for Alloy 718 and higher for Waspaloy and Allvac 718Plus. The cooling rates used in present investigation have not affected the values. The latent heat value for Alloy 718 is on a lower side as investigated in literature.For Alloy 718 Hasse and Antonsson estimated the value to $170 \mathrm{KJ} / \mathrm{Kg}$ [5]. The estimated values and the respective intervals are reported in table 1 . 
Table 1. Latent heat of solidification and solidification range of Alloy 718, Allvac 718Plus and Waspaloy

\begin{tabular}{|lccc|}
\hline Parameter & Alloy 718 & Allvac 718 Plus & Waspaloy \\
\hline Latent heat of solidification $[\mathrm{kJ} / \mathrm{kg}]$ & 152 & 346 & 227 \\
\hline Solidification interval $\left[{ }^{\circ} \mathrm{C}\right]$ & 175 & 190 & 100 \\
\hline
\end{tabular}

\section{CONCLUSIONS}

The main conclusions are:

1. Alloy 718 and Allvac 718Plus reveal two exothermic reactions upon solidification whereas Waspaloy reveals one reaction.

2. Alloy $718\left(175^{\circ} \mathrm{C}\right)$ and Allvac 718 Plus $\left(190^{\circ} \mathrm{C}\right)$ have a larger solidification interval in comparison with Waspaloy $\left(100^{\circ} \mathrm{C}\right)$.

3. The latent heat of solidification is lowest for Alloy 718 and largest for Allvac 718Plus with Waspaloy in between.

4. No effects of cooling rate were seen to affect the solidification process of Alloy 718, Allvac 718Plus and Waspaloy in the present study.

5. The exothermic reactions for Waspaloy are difficult to determine as compared to the other two alloys as the differential curve is smoother.

\section{ACKNOWLEDGEMENTS}

This work was carried out at Materials Processing in the Department of Materials Science and Engineering at the Royal Institute of Technology (KTH) in co-operation with GKN Aerospace (former Volvo Aero Corporation) in Trollhättan, Sweden.

I would like to express my sincere gratitude to Dr. Joel Andersson from GKN Aerospace Engine Systemsand thankful for the support of all the staff at Materials Processing Department for their assistance. 


\section{REFERENCES}

[1] Sims C.T., Stoloff N.S., Hagel W.C, Superalloys 2, John Wiley and Sons, ISBN, pp. 0-47101147-9.

[2] Donachie Mathew J., Donachie Stephen J, Superalloys A Technical Guide Second Edition ASM International ISBN 0-87170-749-7.

[3] G.A.Knorovsky, M.J.Cieslak, T.J.Headley, A.D.Romig, Jr., and W.F.Hammetter INCONEL 718: A Solidification Diagram Metallurgical Transactions A, 1987 pp. 2149-2158.

[4] Fredriksson H., Akerlind U, Solidification and Crystallization Processing in Metals and Alloys, John Wiley and Sons, ISBN: 978-1-119-99305-6.

[5] Antonsson T., Fredriksson H, The effect of cooling rate on the solidification of Inconel 718 Metallurgical and Materials Transactions, B(36B), February 2005 pp. 85.

[6] King J.F., McCoy H.E., Rittenhouse P.L, Weldability Evaluations and Weldment Properties of Hastelloy X Oak Ridge National Lab., TN (USA), 1981.

[7] Fredriksson H., Rogberg B., Thermal Analysis for Interpretation of Solidification Cycle Materials Science and Technology, 13(12), 1979, pp. 685-690.

[8] Kennedy, R.L, Allvac 718 Plus, Superalloy for the Next Forty Years, Superalloys 718, 625, 706 and Derivatives TMS (The Minerals, Metals \& Materials Society), 2005.

How to cite this article:

Raza S S. Superalloys: an introduction with thermal analysis. J. Fundam. Appl. Sci., 2015, 7(3), 364-374. 